\title{
APRESENTAÇÃO: A “EMERGÊNCIA” DA AMÉRICA LATINA
}

\author{
Helcimara de Soura Telles \\ Universidade Federal de Minas Gerais \\ mara-telles@,uol.com.br
}

A América Latina possui uma história político-institucional a ser descoberta pela Ciência Política. Mais do que uma região socioeconômica com características similares, ela é dona de heterogeneidade em arranjos institucionais e cultura política. De modo alternativo ao proposto pela teoria da modernização, não se aplica literalmente na América Latina a proposição segundo a qual igual ponto de partida determina as características dos regimes que irão emergir - se autoritário ou democrático. Entre a origem histórica e o ponto político atingido, revelam-se atores políticos, acomodações institucionais e culturais diversas, embora estas possam ser circunscritas pelas estruturas sócio-econômicas.

Desde que a região latino-americana caminhou em direção à construção de regimes democráticos - há quase 3 décadas -, ela conseguiu instalar eleições e mecanismos de seleção de elites políticas de forma rotineira. A ampliação democrática resultou em enorme politização da atividade societal, não obstante a debilidade institucional e partidária tenham promovido líderes políticos personalistas. A renovação política e a ampliação da igualdade geraram projetos de justiça social, através da intervenção estatal, e a introdução de novos partidos significaram processos eleitorais mais competitivos e livres. Mas, há inúmeros desafios democráticos na América Latina. Eleições não são suficientes para preservar a legitimidade do poder. E a institucionalização de procedimentos democráticos não é indicativa de estabilidade política: tal estabilidade pode significar simplesmente a permanência dos mesmos grupos, a falta de alternância de poder e oligarquização da política (BAQUERO, 2000).

Persistem em alguns países da região incertezas no que diz respeito à liberdade, ao pluralismo e aos procedimentos democráticos. Os partidos latino-americanos se constituíram de cima para baixo e, diferente do esperado por Lipset e Rokkan, os interesses das elites acabaram por determinar a competição política. Os partidos latino-americanos originaram-se com forte influência do elitismo, personalismo e clientelismo. Tais características determinaram sua natureza, bem como a evolução e as funções que por eles foram cumpridas. Esta dinâmica afetou o comportamento eleitoral dos cidadãos (RUIZ, 2013). 
A volatilidade das preferências eleitorais na América Latina a distingue de outras democracias. Nesta região, a democracia emergiu com menor presença de partidos políticos programáticos e destacaram-se, sobretudo, afinidades com os eleitores pautadas por vínculos clientelistas ou personalistas. Destarte, a região tem sido abalizada por baixa identificação partidária, conseqüência desta reduzida estruturação programática, o que condiciona o comportamento eleitoral (RUIZ, 2013) e, por conseguinte, a qualidade da representação democrática.

É verdade que o processo eleitoral retornou à região e que somente pelas eleições se chega ao poder. Mas, igualmente é fato que as eleições presidenciais têm sido canais de politização, pois o sistema presidencialista simplifica as escolhas eleitorais. Nas campanhas políticas, observa-se a personalização da competição e a grande relevância das pesquisas como um instrumento para a atração de eleitores. Em função da baixa identidade partidária e da reduzida tradição ideológica, as clivagens mais importantes são centradas em governo versus oposição.

E, outras áreas de debilidade democrática persistem na América Latina, tais como a insuficiência dos Estados Nacionais e os desafios para ampliar a base de sustentação dos Estados. Ao mesmo tempo em que se incluem políticas de combate à pobreza, a desigualdade persevera e, em numerosos países, há conversão ao neo-populismo - resultado do elitismo dos partidos que condicionou e incentivou o personalismo. Neste sentido, a crise de representação na América Latina ocorreria mais por uma questão de insatisfação com a 'oferta' do que por uma inabilidade da demanda para estruturar preferências programáticas.

Merece destaque o tema dos líderes na relação estabelecida pelos partidos com os seus eleitores na construção da representação política institucional latino-americana. As lideranças se valem da comunicação política e se instalam a partir da popularidade. Esta ausência de mediação resulta no predomínio da "lógica de opinião" (CHERESKY, 2007). Esta lógica produz um mal estar na democracia, pois, em função de sua popularidade, os líderes se colocam acima das estruturas partidárias. Nota-se a presença de uma democracia do tipo providencial, que seria uma espécie de "extensão do princípio igualitário" que se traduz na perda da transcendência republicana em proveito de posições igualitárias e fragmentadas e em uma "democracia contínua". Tal democracia supõe a consciência dos direitos, mas que se traduz em desconfiança por parte dos cidadãos com o poder. Os resultados desta democracia contínua - no qual os projetos políticos coletivos são debilitados -, é a substituição da oposição pela imprensa, a troca dos partidos políticos pelas 
assembléias, o protagonismo dos excluídos sociais e uma autonomia da cidadania que não vem acompanhada de um sentido de justiça: "onde não há instituições que regulem os líderes, a ação cidadã pode se converter em fonte anti-politica" (CHERESKY, 2007).

Entre os fatores que corroem a legitimidade da representação política na América Latina, encontra-se a corrupção. Fernando Filgueiras (2013) afirma que o uso inadequado de recursos econômicos na América Latina desvirtua os procedimentos democráticos. E, que os meios de comunicação criam uma "política de escândalo" sobre os casos de corrupção. Todavia, de acordo com Telles et al (2014), a produção de escândalos políticos midiáticos podem eventualmente produzir mais tolerância que crítica à corrupção benefícios diretos e indiretos, pagamento em dinheiro, recompensas etc -, uma vez que a exposição exacerbada da narrativa da corrupção nos meios de comunicação a naturaliza como atributo dos políticos e das instituições de representação, motivando uma espiral de cinismo em relação à prática do "rouba, mas faそ".

Contudo, em que pese o aumento da percepção da corrupção entre os cidadãos latino-americanos, é a percepção sobre economia que mais condiciona as atitudes da cidadania. Embora na última década a região tenha sido marcada por um constante crescimento econômico, as recorrentes crises, a desigualdade e a pobreza são dificuldades que geram dúvidas na região. Os elementos econômicos - tais como desemprego, inflação, crescimento do PIB per capita -, são usuais para punir e premiar os políticos. A percepção da economia tem sido importante no comportamento político dos latino-americanos, sobretudo quando comparada a elementos sociológicos como a classe social e a religião ou com dimensões de ordem psicológica - como a preferência partidária e a ideologia (CAMARGO, 2003; RATTO \& MONTERO, 2003).

Mas, apesar da percepção subjetiva da economia influenciar as atitudes dos latinoamericanos, atualmente o tema dos valores materialistas e pós-materialistas tem impactado os cidadãos desta região de forma diferenciada. "O acréscimo de informações e a expansão da escolarização têm como efeito o crescimento dos recursos cognitivos e políticos dos eleitores e o maior interesse pela política. Mais informados e instruídos, os eleitores se tornaram mais autônomos em relação aos partidos. Esses novos "eleitores partidários" têm mais mobilidade cognitiva, provavelmente inclinam-se a realizar suas escolhas levando em conta os argumentos de campanha e condicionam suas decisões a valores e a issues que não são necessariamente coincidentes com as agendas dos partidos. O eleitor com maior mobilização cognitiva é menos subordinado às informações produzidas pelos partidos, mais atento às campanhas e mais crítico à política.” (TELLES, MUNDIM, LOPES, 2013, 
p. 200) Dessa forma, o desalinhamento aumenta a volatilidade eleitoral e, por isso, a ética e os valores religiosos, combinados com pautas pós-materialistas - como aumento da participação e ecodesenvolvimentismo -, tornaram-se presentes direta e indiretamente na conduta dos cidadãos brasileiros, como observado nas eleições de 2010.

A agenda de pesquisas sobre a América Latina deve, portanto, colocar à prova inúmeras teorias que são comumente aceitas para examinar as democracias pós-industriais mais avançadas. Torna-se necessário verificar a validade e a aplicabilidade de esquemas analíticos apropriados para outras áreas, mas ainda não testados na América Latina. A percepção da corrupção, a violência, o federalismo e a construção das políticas públicas realizadas nos embates entre as classes sociais e o Estado, são algumas das inúmeras possibilidades de agenda, contempladas neste dossiê. Os artigos oferecem análises de aspectos históricos, do conflito entre os interesses de classes e a economia, bem como a ênfase nas atitudes dos indivíduos, aferidas por entrevistas e surveys com elites políticas e cidadãos.

A despeito dos temas apresentados nos artigos deste dossiê serem diversos, eles se assemelham no que diz respeito à busca por uma explicação das implicações destes elementos na democracia. Seja no exame da participação de economistas como agentes políticos que tomaram parte de governos no Chile, seja verificando a associação entre a qualidade democrática e a percepção da corrupção por parte dos cidadãos latinoamericanos, ou mesmo no exame da centralização/descentralização no México. Especialmente no caso brasileiro, a politização e propagação dos imaginários criminais no contexto democrático, e os alinhamentos e desalinhamentos entre as classes rurais e burguesas, que afetaram a construção de um projeto modernizador para o Brasil.

Observa-se que a democracia encontra-se na regão em diferentes estágios institucionais e que a demanda também é diversificada. Estudo realizado pelo PNUD (Programa das Nações Unidas para o Desenvolvimento), em 2004, que abarcou 18 países (Argentina, Bolívia, Brasil, Chile, Colômbia, Costa Rica, Equador, El Salvador, Guatemala, Honduras, México, Nicarágua, Panamá, Paraguai, República Dominican, Uruguai e Venezuela), demonstra a existência de perfis que não são semelhantes, no que diz respeito à adesão à democracia. O marco teórico do estudo incluiu pesquisa de opinião, indicadores sobre o estado da democracia e entrevista com líderes e intelectuais da América Latina.

Conclui-se que a preferência pela democracia é baixa e que parte significativa dos latino-americanos valoriza mais o desenvolvimento econômico à democracia e que retiraria o seu apoio a um governo democrático, caso ele fosse capaz de resolver os problemas 
econômicos. Para afinar este dados, nota-se ainda que existem três tendências: os democratas, que são favoráveis à democracia em todos os assuntos consultados pela pesquisa, os não democratas e os ambivalentes. Estes perfis ocupam países distintos e de regiões mais ou menos polarizadas na América Central, nos Países Andinos e no Cone Sul.

Mas esta pesquisa chama a atenção pelo fato de que, embora os democratas sejam ligeiramente superiores na América Latina, os cidadãos ambivalentes preferem uma liderança de base democrática, mas com traços que, embora autoritários, aumentem a eficácia da sua gestão, o que poderia ser eventualmente capitalizado pelos adversários da democracia. Esta é outra das razões que nos levam a crer que a América Latina deve ser redescoberta pelas agendas de pesquisa brasileiras. Entre os inúmeros avanços destacados na região no que diz respeito à democracia, ainda persistem zonas de fragilidades políticas que podem ser antecipadas por pesquisas que levem em conta a diversidade institucional e cultural da região. Finalmente, é importante notar que a agenda de pesquisa, apesar de vasta, depara-se também com a dificuldade de uma interpretação que não seja unicausal. Os semelhantes pontos de partida não garantem a certeza dos mesmos resultados políticos nem na América Latina nem outras regiões e as teorias devem ser revistas sempre para garantir a qualidade dos resultados das pesquisas com o uso de adequadas metodologias. E, é isso o que se propõe neste dossiê.

\section{Referências bibliográficas}

BAQUERO, Marcelo. 2000. A vulnerabilidade dos partidos e a crise da democracia na América Latina. Porto Alegre: Editora da Universidade Federal do Rio Grande do Sul.

CAMARGO, Malco. 2013. Refinando a teoria do voto econômico: América Latina revisitada. In: TELLES, Helcimara de Souza; MORENO, Alejandro. (Org.) Comportamento Eleitoral e Comunicação Política na América Latina: o eleitor latino-americano. Belo Horizonte: Editora UFMG. pp. 53 - 81

RATTO, Celeste; MONTERO, José Ramon. 2013. O comportamento eleitoral dos argentinos: algumas chaves das eleições presidenciais de 2007. In: TELLES, Helcimara de Souza; MORENO, Alejandro. (Org). Comportamento Eleitoral e Comunicaşão Política na América Latina: o eleitor latino-americano. Belo Horizonte: Editora UFMG. pp. 109 - 151

CHERESKY, Isidoro (org). 2007. Elecciones presidenciales y giro político en América Latina. Buenos Aires: Ediciones Manantial.

FILGUEIRAS, Fernando. 2013. Corrupção e cultura política: a percepção da corrupção no Brasil. In: TELLES, Helcimara de Souza; MORENO, Alejandro. (Org). Comportamento 
Eleitoral e Comunicação Política na América Latina: o eleitor latino-americano. Belo Horizonte: Editora UFMG. pp. 221 - 258

RUIZ, Letícia. 2013. Oferta partidária e comportamento eleitoral na América Latina. In: TELLES, Helcimara de Souza; MORENO, Alejandro. (Org). Comportamento Eleitoral e Comunicação Politica na América Latina: o eleitor latino-americano. Belo Horizonte: Editora UFMG. pp. 25 - 52

TELLES, Helcimar de Souza; MUNDIM, Pedro; LOPES, Nayla. 2013. Internautas, Verdes e Pentecostais: novos padrões de comportamento político no Brasil. In: TELLES, Helcimara de Souza; MORENO, Alejandro. (Org). Comportamento Eleitoral e Comunicação Politica na América Latina: o eleitor latino-americano. Belo Horizonte: Editora UFMG. pp. $152-220$.

TELLES, Helcimara de Souza; FRAIHA, Pedro; LOPES, Nayla. 2014. Meios de comunicação, corrupção e redes sociais nas eleições para prefeito no Brasil. In: Isabel Ferin Cunha; Estrela Serrano. (Org.). Cobertura jornalística da corrupção política: sistemas políticos, sistemas mediáticos, enquadramentos legais. Lisboa: Aletheia Editores, p. 152 - 220. 